\title{
Falsidade e fabulação em plataformas de compartilhamento de vídeos
}

//////////// Sonia Montaño ${ }^{1}$

Suzana Kilpp ${ }^{2}$

1. Professora no curso de Comunicação Digital da Unisinos. Jornalista, Mestre e Doutora em Comunicação. Email: soniamontano@gmail.com.

2. Professora e pesquisadora no Programa de Pós-graduação em Comunicação da Unisinos. Doutora em Comunicação. Email: sukilp@ unisinos.br. 
Resumo O artigo pensa o estado-vídeo do audiovisual contemporâneo em um lugar de passagem: as plataformas de compartilhamento on-line. Analisa vídeos de Guel Arraes e de Michel Gondry, com ênfase na potência do falso e na fabulação como expressão das vizinhanças que eles criam entre imagens e tecnologias, e problematiza as vizinhanças encontradas em vídeos e nas interfaces das plataformas com vistas à necessidade de pensar uma ética das imagens em tempos de globalização.

Palavras-chave Audiovisual contemporâneo, interface; falsidade, fabulação.

Abstract The article thinks the video-state of contemporary audiovisual in a place of passage: online sharing platforms. It analyzes the videos by Guel Arraes and Michel Gondry, emphasizing the power of falsehood and fabulation as expressions of the relationships they establish between technologies and images, and discusses the neighborhoods found in videos and in the platform interfaces aiming at the need to think about the ethics of images in the age of globalization.

Keywords Contemporary audiovisual, interface, falsehood, fabulation. 


\section{Estado-vídeo e contemporaneidade}

Um dos problemas que desafia os estudos da imagem atualmente é epistemológico e metodológico: ao final, de que falamos quando tratamos da imagem e como abordamos esse construto de complexidade crescente? Como apontávamos em outro momento (KILPP, 2012), se antes sabíamos discernir imagens de um tipo e de outro, inclusive as analógicas das digitais, hoje já não compreendemos sequer o que é uma imagem, de qualquer tipo, em sua clássica diferença em relação a um texto, já que tecnicamente estamos tratando de códigos binários programados para serem vistos como uma coisa ou outra. Pensemos no panorama de uma página qualquer da web, por exemplo, encontramos códigos programados para serem vistos como "vídeo", outros como "textos", outros como "propaganda" e outros como comentários dos usuários, ou sugestões de outros vídeos, entre tantos, sendo que essa programação moldura isolando sentidos, separando, nominando, atribuindo significados por uma sobreposição de elementos diferentemente moldurados.

Podemos pensar com Manovich (2006) que a imagem gerada por computador é ao mesmo tempo uma aparência de superfície e um código subjacente. Na superfície, a imagem síntese dialoga com outros objetos culturais imagéticos; enquanto código, ela dialoga com outros códigos informáticos: "A superfície de uma imagem, isto é, seu 'conteúdo', entra em diálogo com todas as demais imagens de uma cultura" (MANOVICH, 2006, p. 362). O código mantém a maior parte dos usuários à margem, à mercê dos que detêm o controle do software. Podemos pensar essa ideia de forma literal, como o autor o faz, pois de fato há poucos que sabem programar, lidar com o código. 
Mas também podemos pensá-lo no sentido de código audiovisual: imagens programadas para serem significadas de tal ou qual modo que precisam ser desprogramadas para compreender como são construídos os sentidos.

A situação é complicada quando pensamos o audiovisual na emergência de dispositivos de produção, edição e compartilhamento, que tornam qualquer usuário também um realizador-montador de vídeos para qualquer mídia, suporte ou plataforma. Quando em plataformas on-line, eles dão a vê-las como o espaço contemporâneo das passagens (de qualquer imagem e texto de qualquer natureza e origem), onde tudo - além de se dar a ver e passar - dispõe-se a ser passado e ser visto como aquela ou outra realização.

Um modo de resolvermos metodologicamente esse impasse é provisoriamente pensarmos no estado-vídeo como propõe Dubois (2004). Para ele, "estado-vídeo é uma forma que pensa" (DUBOIS, 2004, p. 111). O autor resiste a ver os vídeos como um "outro" da televisão ou do cinema, seu lado "vanguarda” ou aquilo que eles não se animam a ser ou assumir. "O vídeo é, na verdade, essa maneira de pensar a imagem e o dispositivo, tudo em um. Qualquer imagem e qualquer dispositivo". Por isso, ele não o pensa como objeto e, sim, como estado, uma forma que pensa: "O vídeo pensa que as imagens (todas e quaisquer) são, fazem ou criam” (DUBOIS, 2004, p. 116).

Refletir em termos de estado-vídeo permite-nos estender uma primeira mirada sobre o audiovisual contemporâneo (aquele que compartilha a mesma época dessa reflexão) e ver como, nele, todo e qualquer vídeo se enuncia audiovisualmente. Analisando materiais específicos, esperamos poder pontuar nesse artigo algumas tendências que nos interessam considerar acerca da potência do falso.

O contemporâneo comparece em Agamben (2009) como o que é capaz de apreender e perceber seu tempo (com suas opacidades) e abrigar outros tempos nele, desde o mais moderno ao mais arcaico. No caso dos vídeos, contemporâneos seriam aqueles que conseguem falar de si, de qualquer mídia e da época em que se realizam, pois na atualidade de suas formas coalescem múltiplas temporalidades, anacrônicas e tensas, sintomáticas das coalescências de "nosso tempo". Nesses termos, podemos dizer que o vídeo digital é o mais contemporâneo de todos os vídeos. E, também, podemos dizer que as 
plataformas de compartilhamento on-line são o espaço privilegiado em que um vídeo se torna contemporâneo.

Nesse sentido, Arlindo Machado (2007) destaca na imagem digital a sua extraordinária capacidade de metamorfose, já que se pode nela intervir infinitamente, subverter seus valores cromáticos, inverter a relação entre figura e fundo, tornar transparentes os seres que ali aparecem. $\mathrm{O}$ autor constata que as imagens ("imagens mestiças", diz ele) estão também sempre migrando de um meio a outro, de uma natureza a outra (pictórica, fotoquímica, eletrônica, digital), a ponto de este trânsito permanente tornar-se, a seu ver, sua característica mais marcante.

Ainda, Bentes (s/d) defende que assistimos à formação de uma verdadeira enciclopédia audiovisual da cultura contemporânea, uma enciclopédia digital que canibaliza imagens (produzidas pelo cinema, televisão, vídeo, teatro, pintura e outros) e devora diferentes tipologias (de imagens e de saberes). A persistente classificação dos vídeos de acordo com as tecnologias empregadas em sua realização, ainda que tenha a vantagem de explicitar algumas especificidades de cada uma (seus modos próprios de construir e experimentar o tempo, o espaço e a figura), corresponderia hoje, quando tudo pode ser reprocessado como informação, a uma classificação "burocrática”.

Assemelha-se, portanto, à tipificação que persiste quanto às disciplinas e aos saberes cartesianos, que vem se mostrando cada vez mais insuficiente e deficiente, enquanto proliferam outras abordagens, inter e transdisciplinares, talvez ainda também insuficientes porquanto nelas perdura a visada disciplinar e regulatória do acontecimento, obscurecendo sua potência como eterno devir (o que inclui a potência do falso).

Mas a autora acredita que o uso de diferentes tecnologias na produção audiovisual opera no sentido da dissolução das fronteiras de cada tecnologia/disciplina. Tratar-se-ia de uma operação cujo efeito não é simplesmente uma combinatória de material préexistente (na pintura, no cinema, no teatro, na televisão etc.), mas, além disso, uma "tradução" de todas as imagens analógicas em imagens digitais, transfiguração e transdisciplinaridade que não aparecem apenas no "efeito" dessas imagens, mas estão na base da sua produção, que utiliza procedimentos emprestados aos saberes os mais díspares, da biologia à balística, passando pela topologia, 
3. A metodologia das molduras implica e articula três eixos conceituais: molduras, ethicidades e imaginários. Os eixos são atravessados pelos quatro conceitos basilares da obra de Bergson (1999), que são a intuição, o élan vital, a duração e a memória, e pelos conceitos de imagicidade e cinematismo propostos

por Eisenstein (1990). Em sua processualidade, o método parte da dissecação das molduras discretas construídas por cada mídia para esconder ou disfarçar as montagens, os enquadramentos etc. com os quais ela deseja atribuir certos sentidos ao conteúdo que veicula. Nas molduras assim cartografadas é então possível autenticar quadros e territórios de experiência e significação das ethicidades (os construtos midiáticos de coisas, fatos, pessoas, acontecimentos etc.), cujo sentido é agenciado por conta dos imaginários minimamente compartilhados entre todos os partícipes de processos comunicacionais, e que podem ser apenas intuídos pelo pesquisador. Nesse agenciamento intuído, pode-se/ deve-se apontar a incidência dos repertórios pessoais e culturais dos espectadores-receptores-usuários no sentido último. neurociência, matemática, geometria fractal etc. "Que conceitos podem dar conta desses objetos indeterminados, a meio caminho entre o sensível e o inteligível, o material e o imaterial, o digital e o analógico?" (BENTES, s.d.), pergunta a autora.

Os autores apontam algumas tendências do estado-vídeo, e, a partir de vídeos de naturezas diversas que analisamos em outro momento (MONTAÑO, 2012) pudemos autenticar as tendências apontadas até aqui: convergência de tecnologias, de mídias, de imagens e de imaginários. Encontramos essas conectividades heterodoxas em um comercial do diretor francês Michel Gondry, em programas televisivos do núcleo Guel Arraes, em produções dos VJs britânicos Coldcut, em vídeos especialmente feitos para a web pelo autor do canal Mysteryguitarman no YouTube, em tantos outros vídeos que estivemos monitorando.

Além dessas, encontramos nos materiais analisados uma outra tendência, na qual as características reincidentes remetem antes à tatilidade do que à visualidade das imagens, e que assim questionam o predomínio da visão na organização do mundo visível. Essas características emergem por excelência nos ambientes que se enunciam como espaço de passagem e convergência de todo e qualquer vídeo, mídia e tecnologia: as plataformas de compartilhamento online. Nelas, o vídeo que antes conhecíamos como tal se reinventa a ponto de não serem mais adequados os termos que praticávamos para dizê-lo vídeo.

Incitados por essas tendências anteriormente autenticadas, a seguir abordaremos algumas características do audiovisual contemporâneo que, a nosso ver, denotam o estado-vídeo. Para a análise, adotamos a metodologia das molduras (KILPP, 2010)³, apontando algumas das principais moldurações no interior delas e através das quais são ofertados sentidos identitários aos vídeos (ou aos elementos técnicos e estéticos constitutivos deles).

\section{O estado-vídeo em Guel Arraes e em Michel Gondry}

Vejamos inicialmente algumas imagens produzidas pelo Núcleo Guel Arraes da TV Globo para um quadro do programa Fantástico.

Elas produzem estranhamento por duas razões: primeiro, porque 
4. Na lógica do meio (como de

resto em qualquer meio), o teor conteudístico (o que se diz) prevalece

na expectação sobre os modos como ele é produzido (como se diz, técnica e esteticamente), que sempre

tende a ficar oculto, em uma zona de opacidade. As lógicas de cada meio para produzir esse efeito são diferentes, mas intentam o mesmo resultado ou efeito.

5. O Núcleo produziu, em sua longa trajetória na TV Globo, vários programas que poderiam ser classificados, nesse sentido, como meta-televisuais: televisão sobre televisão.

6. O quadro está disponível em: http://br.youtube.com/ watch?v=WOAxbFJwmd0. apresentam um tipo de textura que parece dar tatilidade à imagem de TV, uma rugosidade que contrasta com a lisura da tela, ao ponto de levar o teor conteudístico a um segundo plano, tensionando assim a lógica desse meio ${ }^{4}$.

Um segundo aspecto bastante curioso é o extenso leque de imagens utilizadas na montagem - que remete a uma quasecartografia de todas as imagens afins, simulando as produzidas por dispositivos midiáticos e não midiáticos que de alguma forma enunciam a TV como lugar de trânsito das imagens produzidas nos confins mais diversos da cultura.

Apesar de o Núcleo em questão caracterizar-se por dar a ver a montagem televisiva ${ }^{5}$ e assim questionar a continuidade que esta produz, havia, nesse exemplo, um tipo de apropriação e de intervenção nas imagens mais próprio dos meios digitais do que da televisão.

Fazendo uma dissecação mais detalhada das imagens, achamos importante destacar o que intuímos a partir dos frames das Figuras 1 e 2 (capturados de um episódio do Sexo Oposto ${ }^{6}$ exibido em 6 de abril de 2008). O quadro abre com um claro enunciado: "isso é televisão!". Holofotes, monitores, câmeras de diversos ângulos, bastidores, "ao vivo" (das personagens, não do programa) oferecem sentidos identitários à TV. Mais especificamente, apresentadores, bancada e teleprompter oferecem sentidos identitários ao telejornalismo. A TV e o telejornal são construídos como ethicidades nos confins do programa.

Contudo, no que interessa aqui, há já no início tensionamentos ao televisivo e ao telejornalismo, elementos que dificilmente estão em programas ao vivo e de notícias a que se refere o teor do quadro. Esses tensionamentos acontecem principalmente pelas intervenções gráficas feitas em computador sobre a imagem.

Por exemplo, no primeiro e quarto frame da Figura 1, há um enquadramento em que se vê a bancada do estúdio e suas dimensões junto aos outros elementos que compõem a imagem. Está clara a presença de atores, apesar de que essas imagens estão sendo tensionadas o tempo todo pela presença de gráficos (como podemos ver no quarto frame). Esses gráficos aparecem dando visibilidade a palavras, a pensamentos e a movimentos dos apresentadores, algo que nunca é visto em telejornais, nos quais os gráficos estão geralmente moldurados como um recurso didático para que o 
Figura 2 - Um frame do Jornal Nacional, com destaque para o lugar da bancada e a diferença da bancada

de Sexo Oposto. Um frame do desenho Os Flintstones, com destaque para a estética, e suas relações com a estética do quadro em questão.

FONTE: YouTube, 2011;

Montagem feita pelas autoras a partir de vídeos disponíveis em: https://www.youtube.com/ watch?v=xsYKlRgGAlQ; https://www. youtube.com/watch?v=PWdLdT62 e8\&list=PL3258607993D85B20

e https://www.youtube.com/ watch?v=T2Xgiuz5BzA.

7. Convém lembrar que sempre se trata de ethicidades, de construções televisivas de tais saberes.
Ao longo de todo o quadro há também uma estranha combinação entre a roupa dos apresentadores e a bancada ou o fundo. A ethicidade bancada do Sexo Oposto parece ser bem diferente da bancada por excelência do Jornal Nacional, referência para todos outros programas informativos dessa emissora e de outras. Como mostram os dois primeiros frames da Figura 2, ao mesmo tempo em que ela significa mesa de relatar, dos apresentadores, separados do resto da redação e suas mesas de redigir, ela é moldura de todas as mediações e costuras de fragmentos de informação, e é também desde onde um telejornal, via seus apresentadores, relaciona-se com os espectadores.

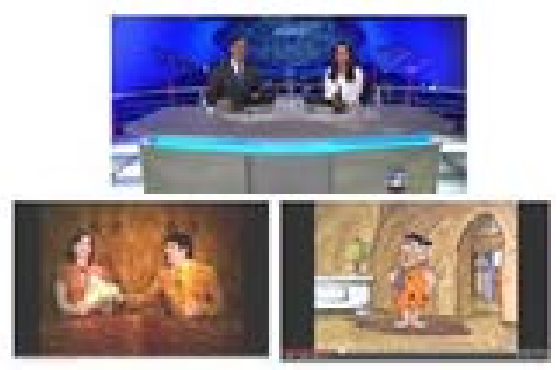

Na Figura 2, há um frame da abertura do Jornal Nacional seguido de mais um frame da abertura do quadro Sexo Oposto e outro do desenho animado Os Flintstones, que tomamos a liberdade de associar às demais porque foi o que a textura dominante na bancada, nos fundos e nas roupas dos atores nos evocaram. A bancada do JN reforça sentidos de objetividade jornalística com a presença de notebooks e material de leitura (primeiro e segundo frame da Figura 2). Em total contraste (no terceiro frame da Figura 2), a bancada do Sexo Oposto, está vazia, (imagem que, aliás, não se vê em nenhum telejornal), e parece não ter profundidade (terceira dimensão aparente) e se constituir em uma fina superfície bidimensional que se enuncia, ao final, como falsa bancada de um falso telejornal que é, no entanto, a nosso ver, a verdade do quadro.

No episódio em questão desse quadro do Fantástico o conteúdo da ethicidade matéria jornalística é o cérebro (de homens e de mulheres), e, para ilustrar, são evocadas imagens oriundas da medicina nuclear (primeiro e segundo frames da Figura 3), da pintura (terceiro a quinto frames), da fotografia (sexto e sétimo frames) e de revistas impressas (oitavo frame). O teor refere-se a diferenças cientificamente constatadas e objetivamente relatadas por jornalistas ${ }^{7}$ entre o cérebro masculino e 
Figura 3 - Sexo Oposto - imagens de diversas naturezas Fonte: YouTube, 2010, disponível em: https://www.youtube. $\mathrm{com} /$ watch?v=PWdLdT62 e8\&list=PL3258607993D85B20.
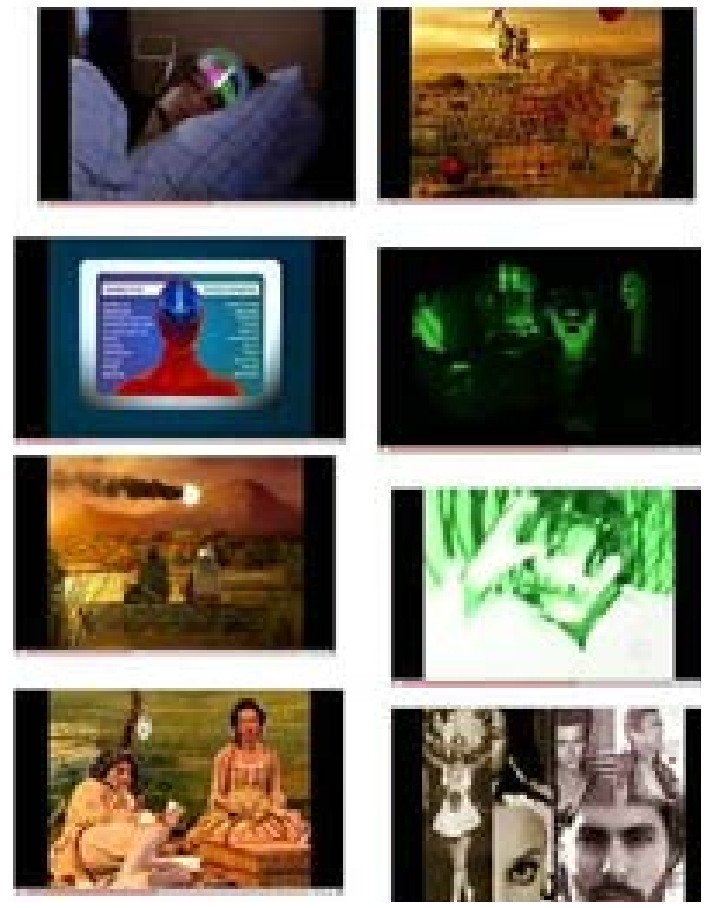

feminino, entre o hemisfério direito e o hemisfério esquerdo, o lugar da criação, da emoção e da imaginação e o lugar da lógica e da razão.

Mas, muito mais do que fazer parecer-se a um programa educativoinformativo sobre as funções do cérebro humano, o quadro parece referirse ao "cérebro televisivo" da era digital, um cérebro em que as fronteiras e funções distintas dos dois hemisférios se dissipam, e as mesmas imagens podem comparecer em qualquer um deles se estivermos abertos a aceitar as intervenções que hoje são tecnicamente possíveis. Assim, o lado direito - do entretenimento, do humor e da criação - e o lado esquerdo - crítico e intelectual - parecem o ser mesmo, ou indistintos, na tessitura televisiva.

Nessa perspectiva e no que interessa aqui, Sexo Oposto fabula sobre arranjos de imagens habitualmente disjuntivas que levam à percepção tátil de mundos televisivos e que assim também fabula sobre seu limiar. São imagens justapostas que devoram os sentidos tradicionais de imagens de uma mídia ou de outra, de um suporte ou tecnologia ou de outro. Remete a outro sentido, mais complexo, de coleção, inventário, banco de dados e interação imagética com repertórios de telespectadores-usuários, e, desde exatamente esse lugar, imagina mundos também mais complexos.

McLuhan e Powers (1993, p. 101) já alertavam que o homem 8. E, até antes, Benjamin (2012). tecnológico perderia o tato, ou melhor, se daria conta de que o "o tato 
9. Tradução livre do original: "el tacto no es sólo una presión en la piel sino

la captación de todos los sentidos al mismo tiempo, una especie de "tactilidad".

10. Disponível em: http:// www.youtube.com/ watch?v=7go8XFvU4BU. Acesso em: 13 fev. 2012.

11. Personagens de si mesmos.

\section{Assista o vídeo}

Figura 4 - Comercial da HP produzido e protagonizado por Michel Gondry Fonte: YouTube, 2009, disponível em https://www.youtube.com/ watch?v=iLwkNa35JtA não é simplesmente a pressão sobre a pele e, sim, a captação de todos os sentidos ao mesmo tempo, uma espécie de tatilidade"9. Tratar-seia, talvez, de uma tatilidade programada por softwares, como nos leva a pensar Manovich (2008). Mas preferimos pontuar que as imagens televisivas do Núcleo Guel Arraes tendem mais a acentuar seu caráter de imagem-interface, da qual trataremos adiante.

Vejamos a seguir um outro caso, que é o comercial de notebooks HP roteirizado, produzido e protagonizado por Michel Gondry e disponível na plataforma YouTube ${ }^{10}$. Assim como no caso anterior, havia uma moldura bastante sólida - o telejornalismo -, que é a inscrição do vídeo no gênero publicidade, o que confere desde o início um sentido comercial aos arranjos entre o computador, a marca e o ator-diretor. Como no caso anterior, porém, tal sentido é tensionado pelo caráter lúdico e experimental que conota a obra, especialmente no que diz respeito à ambiguidade das enunciações sobre marcas, computadores e publicitários-usuários do computador dessa marca, situados todos também, imageticamente, em um limiar em que a fronteira distintiva entre um e outro é indiscernível.

O comercial faz parte da campanha HP - the computer is personal again, em que artistas, escritores, esportistas, músicos, empresários e inclusive personagens de ficção falam sobre suas atividades e sobre o lugar do computador no seu dia a dia. As peças da campanha de modo geral têm em comum algumas técnicas de montagem: o enquadramento da persona ${ }^{11}$ em plano americano (ver Figura 4), sem incluir a cabeça; as falas dos protagonistas acompanhadas de imagens de seus movimentos de mãos; a emergência de imagens relacionadas ao cotidiano da persona em questão. No final, aparece quase como

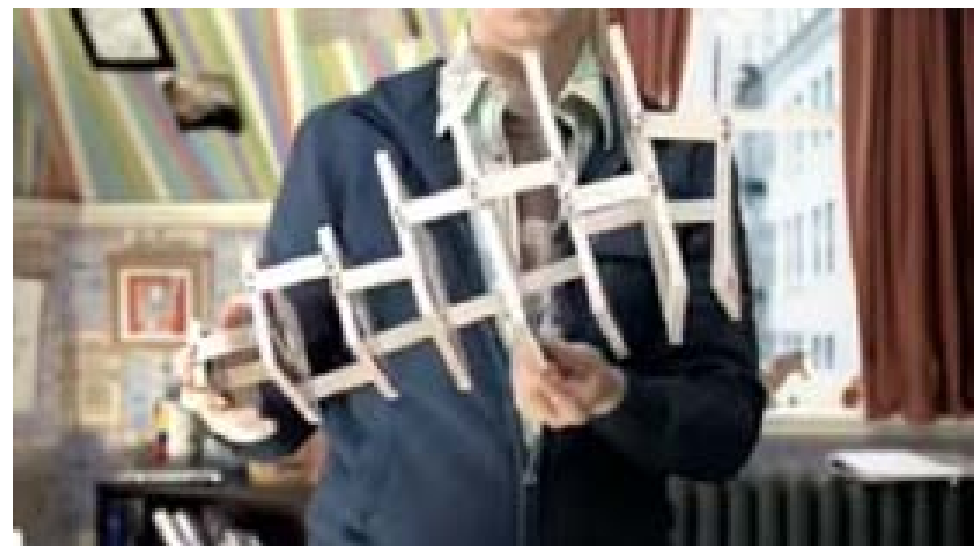


12. Como se explica no making of da peça, Gondry (que é conhecido por suas experimentações em vídeo) criou, ele mesmo, o roteiro e a música, e o comercial foi dirigido por seu irmão. Disponível em http://www.youtube.com/ watch?v=1N7P9POXuFE. Acesso em: 13 jun. 2012. assinatura da campanha a legenda: HP the computer is personal again, enquanto se abre o enquadramento da última cena mostrando que ela está acontecendo na tela de um notebook, ambiguamente: é a persona que fala do lugar do computador em sua vida ou é o computador que contém a persona em seus mundos virtuais? Ou seja, o sítio da interface é a questão que permeia toda a campanha.

O comercial de Gondry foi escolhido por nós para pensar o estadovídeo particularmente porque nele se enuncia o lugar dos dispositivos comunicacionais no universo do audiovisual contemporâneo. Em todas as peças da campanha, reitera-se como teor a convergência digital de sons e imagens, de diferentes origens, realizada por computadores. Na de Gondry, antes disso, destaca-se do teor o modo como ele próprio, Gondry, os objetos e as imagens se modificam, outralizam-se, convertem-se em outra coisa incessantemente ${ }^{12}$.

$\mathrm{O}$ vídeo inicia com o plano americano do diretor em frente à câmera. Ele se encontra em um ambiente que poderia ser seu quarto ou escritório. O ambiente está poluído de objetos, papéis e cores que, em diversos momentos do comercial, adquirem movimento. Esse cenário remete diretamente ao filme Sonhando acordado (The Science of Sleep, 2006), do mesmo diretor. No filme, assim como no comercial da HP, há uma estética artesanal típica de Gondry, com objetos de algodão, papel, pano, madeira e animações em stopmotion de objetos feitos de papelão. Em ambos, esses objetos "vivem" experiências cotidianas em cenários surreais e fantásticos.

A maior parte do comercial desenrola-se em um enquadramento fixo, como é próprio dos atuais gêneros que vão emergindo do uso da webcam: a câmera está aí, ligada, e a vida vai se desenrolando diante dela, e não o contrário, como é próprio do cinema e de boa parte da TV, e mais na linha da célebre frase de Glauber Rocha: "Uma câmera na mão e uma ideia na cabeça”. Com tal enquadramento (que é uma moldura!), o comercial reúne virtualmente toda uma variada produção de vídeos que usam a webcam, a persona que fala em primeira pessoa e um fundo, geralmente o dormitório, tudo enquadrado com um único plano fixo. Assim, o comercial pode ser pensado simultaneamente como um videolog (de alguém que reflete sobre alguma coisa), como um tutorial (de alguém que ensina a fazer alguma coisa) ou como um lifecasting (de alguém que transmite o que está fazendo), alguns dos gêneros emergentes desde que se tem 
13. Termo usado no cinema e no teatro para definir representações de si dos atores na vida real câmeras incrustadas em computadores ou celulares.

Ao plano visual sobrepõe-se a voz de Gondry: "eu gosto de experimentar com filme, com animação e efeitos digitais”. A partir desse momento, entram em cena "três Gondrys" personagens tecnicamente diferentes, que estarão presentes em todo o comercial: uma primeira, sua imagem feita em live action ${ }^{13}$; uma segunda, sua imagem em stop-motion; uma terceira em animação 3D. Essas três imagens técnicas instauram a persona Gondry como um ser multifacetado.

Na primeira sequência, então, há uma correspondência entre Gondry e a fala "eu gosto de experimentar com filme" - é o Gondry live action. Ele tira a tesoura do bolso e vai se convertendo em stopmotion enquanto diz "animação". E transforma-se em animação 3D quando diz "efeitos digitais". Este último Gondry corta a cena com a tesoura que tira do seu bolso como se fosse papel (ver Figura 4).

A mutação dos Gondrys é acompanhada de sons característicos, a tesoura cortando tem um som próprio, assim como no computador há sonoridades diversas para expressar diferentes movimentos; é assim que a abertura do comercial tem o som de um computador quando ligado, e a sonoridade da voz de Gondry vai se transformando à medida que o vídeo avança.

O comercial parece dar voz a cada objeto e a cada situação ou alteração que acontece dentro do seu universo. A tesoura, por exemplo, protagoniza a cena em que aparece, e, ao corte, perguntase se isso que ela corta é papel? É desenho? É virtual? É real? A sobreposição dessas imagens e desses sons produzem narrativas paradoxais e indiscerníveis em relação à materialidade e à realidade dos objetos; ou seja, por exemplo, o real sugerido é o da imagem tornada papel, que consegue vencer os três Gondrys, os quais se limitam a seguir o curso da tesoura. A cena remete à lógica do jogo infantil "pedra, papel e tesoura”, que é movimentado pelas mãos de dois jogadores que alternam competitivamente a figuração das três materialidades: tesoura corta papel, pedra quebra tesoura, papel envolve e paralisa o corte da tesoura. Esse jogo, como todo o jogo que tem um forte componente de azar na sua lógica, enuncia sentidos de circularidade, de ausência de hierarquia para todos os elementos que compõem a cena: o acaso pode favorecer qualquer um. Ao mesmo tempo, como todos os jogos tem um componente 
de competição, ele enuncia a seriedade do jogo tão referida por Huizinga (2004): joga-se para ganhar.

A convergência do computador e do vídeo com o realizador (justo na hora em que Gondry diz "meu computador conecta os três mundos") está sendo enunciada aqui como limiar, e é no limiar de vizinhanças e parentescos que o falso emerge com toda sua potência discursiva.

Há vários indícios no vídeo de que os mundos referidos por Gondry sejam o humano, o dos dispositivos computacionais e o do audiovisual, interfaceados indiscernivelmente no comercial da HP. Sua contemporaneidade pode ser, então, assinalada nas seguintes características, dentre as quais destacaremos a função do som.

A sonoridade do comercial, própria dos ambientes sociais da internet e do computador, dá sentidos de imersão e de tatilidade, de se estar conectado, interagindo com os dispositivos computacionais e alternando janelas para o "virtual" e para o "real". O som se atualiza no comercial, mas também no computador e na vida on-line, assim como os sinais de trânsito off-line.

Quando acionamos o botão para ligar o computador, ele nos confirma que de fato ligou com um sinal sonoro próprio do sistema operacional que usamos. Quando alguma operação dá erro, vem aquele som abrupto, desagradável. Ao som de um e-mail que chega, abrimos essa janela para lê-lo. Ou seja, o som nos conduz, mas também nos dá antecipadamente sentidos de comemoração ou catástrofe. Cada vez mais, ele é explorado nas relações entre computador e usuário, especialmente entre esse usuário e a web.

O design do som visa uma imersão na imagem e um reconhecimento rápido de sons familiares para que não precisemos de nenhuma outra referência para entender sua mensagem. Ele nos introduz num espaço acústico-tátil próprio dos meios elétricos, como lembravam Carpenter e McLuhan:

El espacio auditivo no tiene ningún foco preferente. Es una esfera sin fronteras fijas, un espacio construido por la cosa misma, no un espacio que contiene la cosa. No es espacio pictórico, encerrado, sino dinámico, siempre fluyente, que crea sus propias dimensiones momento tras momento. No tiene límites fijos, es indiferente al fondo. El ojo enfoca, 
señala, abstrae, localizando cada objeto en el espacio físico contra un fondo; el oído recoge el sonido procedente de cualquier dirección. Escuchamos igualmente bien si ese sonido viene de la derecha o de la izquierda, de delante o de atrás, de arriba o de abajo. No importa que estamos tendidos, mientras que en el espacio visual todo el espectáculo se altera. Podemos cerrar el campo visual, cerrando simplemente nuestros ojos, pero estamos siempre obligados a responder al sonido (MCLUHAN, 1974, p. 60).

Assim como as diversas tecnologias que engendram as imagens, o design do som convida a "tocar" as imagens. E, na cena que estamos analisando, não apenas os sons, mas também os vários Gondrys, os objetos e as texturas convidam ao "toque".

Quase no final, fecha-se o enquadramento na imagem da cabeça do diretor-ator sobre um travesseiro, aparentemente dormindo. Ao "acordar", ele diz: "sonho muito, embora não durma muito bem". Quando o enquadramento volta a abrir, em três camas aparecem lado a lado os três Gondrys e a legenda "Michel Gondry, eterno sonhador". Enquanto o enquadramento segue abrindo percebe-se que a cena desenrola-se na tela de um notebook, e uma voz em off diz "o computador volta a ser pessoal". A cena finaliza com uma imagem gráfica da marca da HP.

Dentre tantas molduras, ethicidades e imaginários convocados por essas imagens, gostaríamos de nos deter em duas enunciações no construto: o computador como metamídia e a fabulação das imagens gondryanas.

Deleuze (1990) já falava da fabulação presente na imagem-tempo, uma ruptura que não está entre a ficção e a realidade, mas no novo modo de narrativa que as afeta. É a potência do falso o que constitui a fabulação:

A ficção é inseparável de uma "veneração" que a apresenta como verdadeira, na religião, na sociedade, no cinema, no sistema de imagens. Ninguém entendeu as palavras de Nietzsche, "elimina tuas venerações", tão bem quanto Perrault. Quando Perrault se dirige a suas personagens reais do Quebec, não é apenas para eliminar a ficção, mas para libertá-la do modelo de verdade que a penetra, e encontrar ao contrário a pura e simples função de fabulação 
14. Em nossa cultura, há uma associação quase imediata da ideia de presépio à imagem bíblica do presépio em que nasceu Jesus Cristo. que se opõe a esse modelo. O que se opõe à ficção não é o real, não é a verdade que é sempre a dos dominantes ou dos colonizadores, é a função fabuladora dos pobres, na medida em que dá ao falso a potência que faz deste uma memória, uma lenda, um monstro. (...) O que o cinema deve apreender não é a identidade de uma personagem real ou fictícia, através de seus aspectos objetivos e subjetivos. É o devir da personagem real quando ela própria se põe a "ficcionar", quando entra "em flagrante delito de criar lendas", e, assim contribui para a invenção de seu povo (DELEUZE, 1990, p. 183).

O autor propõe que uma forma do cinema poderia se chamar cinema-verdade, que passa ao lado da verdade representada para tornar-se sua própria verdade, a verdade do cinema.

Já o computador e a imagem-interface atualizam a verdade da fabulação e do falso, em outros termos. E é também em outros termos que Agamben (2007) discute a mesma questão a partir, por exemplo, da imagem premera e secularizada de presépio $^{14}$ : como fábula, é uma imagem que se encontra entre o encanto e a história, a imagem de um "instante messiânico desta transição” (AGAMBEN, 2007, p. 153). Diante do presépio, o "homem" emudece e a "natureza" toma a palavra. São esses elementos - palavra e silêncio, divino e profano, história e natureza - que articulam a discussão do autor sobre a fabulação. O presépio marcaria um específico acontecimento histórico no qual simultaneamente se reencontraria marcas e registros (ou evidências) de figuras transcendentes e magicamente conectadas a todas as coisas em qualquer momento da história.

Assim também as imagens de Gondry enunciam o computador como fabulador, e a fabulação seria a realidade das imagens feitas em computador. Na obra de Gondry há uma ética-estética que fabula sobre a pluralidade do eu, dá vez e voz a seres inanimados, dissolve fronteiras, evoca sonhos e infâncias, produz imagens contemporâneas nas quais todas as coisa habitam o mesmo tempo-espaço.

\section{Dos vídeos às plataformas de compartilhamento on-line}

Os vídeos abordados apontam algumas tendências do estado- 
vídeo, e não remetem ao YouTube simplesmente pelo fato de eles serem encontrados lá, como frequentemente se tende a pensar. É cada vez mais comum que, se temos a intenção de assistir a um vídeo (qualquer), sejamos remetidos às plataformas de compartilhamento on-line, o habitat por excelência do vídeo, o sítio ou arquivo aonde mais provavelmente o vídeo pode ser encontrado.

Mas também sabemos que nesse lugar encontraremos remix desses vídeos, que se confundem por vizinhança e enunciação. Ou seja, as tendências que encontramos no interior de um vídeo tendem também a aparecer nas plataformas, numa interface que age sobre os vídeos e sobre os usuários-realizadores. É principalmente nas plataformas que o vídeo é enunciado como um processo e não um produto.

Ao assistir a um vídeo na internet geralmente se passa pela moldura player, que nos cega para o construto da interface em que ela se encontra. Por isso, muitas vezes não nos damos conta, por exemplo, de que os vídeos nunca são apenas eles: eles são parte de uma coleção de vídeos aparentados segundo a lógica operativa do site que é sugerida na interface ao lado de comentários, links dentro e fora deles e que remetem a outros vídeos, no "canal" conectado ou em outros. Sem que nos apercebamos, isso interfere profundamente na experiência, e afeta sensivelmente nossa percepção, que se torna mais conectiva (segundo os critérios de conectividade programados para a interface).

Fazer um login no YouTube, por exemplo, significa dar início a uma coleção (programada) de vídeos, de comentários (programados) e de amigos (programados), a partir de uma "busca" que pensa o mundo através de palavras-chave ou etiquetas.

É dessa mesma forma (programada) que emerge das plataformas o que estivemos até aqui chamando de audiovisual contemporâneo: um construto (ethicidade) das plataformas on-line. Compreendêlo demanda relacionar entre si quatro outras ethicidades também contemporâneas: vídeos, interfaces, usos e ambientes. Dessa relação emerge uma imagem virtual (nos termos de Bergson, 1999), uma imagem dialética (nos termos de Benjamin, 2006), uma audiovisualidade. Na internet, os vídeos a que assistimos na moldura player não podem ser entendidos independentes do conjunto de ethicidades-molduras sobrepostas: o vídeo e o player estão inseridos numa interface que os ressignifica, inclusive com sentidos nela enunciados para os usos e os usuários nela enunciados. 
Johnson (2001, p. 9) define a interface como o universo de relações que fazem o funcionamento de alguma coisa, "todo o mundo imaginário de alavancas, canos, caldeiras, insetos e pessoas conectados - amarrados entre si pelas regras que governam esse pequeno mundo". É o encontro de sistemas ou mundos diversos neste caso, o do humano, o do computador e o do audiovisual -, mas também é o encontro do usuário com mundos on-line e off-line. $\mathrm{Na}$ interface aponta-se (e restringe-se) os usos possíveis, e, quando os usuários transgridem esse programa criando novos usos, estes tendem a ser rapidamente incorporados e novamente interfaceados, numa crescente complexificação do jogo entre aparelho e usuário, nos termos de Flusser (2002).

No atual estágio da técnica (e do jogo), a interface moldura o vídeo como um processo, produto in process que convida à constante intervenção de usuários à conectividade de imagens e usuários, principalmente através da cópia (embora no discurso institucional da plataforma, a "cópia” seja banida). No processo, usos e interfaces se outram e outram o vídeo, reciprocamente, e essa dinâmica instaura um ambiente, de passagem, do vídeo contemporâneo, em fluxo, in process.

\section{Considerações finais}

A interface on-line parece ser a moldura das molduras do audiovisual contemporâneo. No atual estágio da técnica, ela parece ser a moldura das molduras de uma nova mídia, embora players e telas bem delimitadas insistam em oferecer antigos sentidos de cinema, TV e vídeo ao vídeo enunciado nas plataformas on-line.

Mas suspeitamos que algo inusitado pode estar acontecendo aí, algo que vai além das explicações que temos dado ao fenômeno, algo que incide sobre o ponto zero do aparecer do vídeo nas plataformas de compartilhamento.

Parafraseando McLuhan, talvez esteja na opacidade da interface a mensagem da mídia constituindo-se. Nessa perspectiva, à primeira vista nos parece que ela seria um espaço mais acústico do que visual, no qual as relações entre figura e fundo precisariam ser tatilmente percebidos em sua diferença e, então, mais bem definidos e significados, pois pensamos já ter dado mostras suficientes de que 
15. As diferenças de grau e de natureza a que nos referimos estão consubstanciadas em Bergson (1999).

16. Para maiores esclarecimentos, ver anotações de Benjamin (1994) sobre o autor como produtor. não se trata apenas de relações entre vídeos, compreendidos todos eles como figuras que só diferem de si em grau.

Furtando-nos de avançar sobre as diferenças de natureza ${ }^{15}$ das figuras, mesmo em se tratando apenas de vídeos circunvizinhos (que são tornados vizinhos ou aparentados pela programação da plataforma que os coleciona sob tags estatisticamente constatadas ou presumidas pelo software) é urgente, no âmbito e escopo do artigo, tecer algumas considerações finais sobre os vídeos analisados na perspectiva a que nos propusemos considerar. Assim, face ao falso e à fabulação que são intrinsecamente constitutivos do presumido novo meio e que são acelerados pelo uso alargado do remix, há que se colocarem algumas questões acerca das imagens montadas por Gondry e Arraes.

Em um estágio anterior da técnica não teríamos dúvidas em defender sua potência. Diríamos - e até continuamos a dizer que suas experimentações continuam a fazer avançar as técnicas, porquanto ensinam a outros realizadores sobre a técnica ${ }^{16}$. Mas, o falso, tão reiterado simbolicamente nos vídeos circunscritos às interfaces das plataformas de compartilhamento de vídeos, teria a mesma potência?

Para responder a essa questão talvez seja necessário refletir melhor sobre os atravessamentos resultantes da produção de vizinhança de vídeos na interface, e discernir até onde podemos reconhecer a hospitalidade ou a hostipitalidade (nos termos de Derrida, 2003) nas e entre as imagens. 


\section{Referências}

AGAMBEN, Giorgio. Que es um dispositivo? Disponível em: $<$ http://www.scribd.com/doc/16816242/Agamben-GiorgioQue-es-un-dispositivo>. Acesso em: 23 Abr. 2010.

AGAMBEN, Giorgio. Profanações. São Paulo: Boitempo, 2007.

BENJAMIN, Walter. A obra de arte na época de sua reprodutibilidade técnica. Porto Alegre: Zouk, 2012.

BENJAMIN, Walter. Magia e técnica, arte e política. São Paulo: Brasiliense, 1994.

BENJAMIN, Walter. Passagens. Belo Horizonte: Editora UFMG, 2006.

BENTES, Ivana. Do modelo industrial ao biotecnológico. (s/d.) Disponível em <http://www.bocc.uff.br/pag/bentesivana-industrial-biotecnologico.pdf>. Acesso em 10 set. 2008.

BERGSON, Henri. Matéria e Memória. São Paulo: Martins Fontes, 1999.

CARPENTER, Edmund. MCLUHA, Marshall. El aula sin muros. Investigaciones sobre técnicas de comunicación. Barcelona: Editorial Laia, 1974.

DELEUZE, Gilles. A Imagem-Tempo. São Paulo: Brasiliense, 1990.

DERRIDA, Jacques. Da hospitalidade. Coimbra, Palimage, 2003;

DUBOIS, Philippe. Cinema, vídeo, Godard. São Paulo: Cosac Naify, 2004.

FLUSSER, Vilém. Filosofia da Caixa Preta. Ensaios para uma futura filosofia da fotografia. Rio de Janeiro: Relume Dumará, 2002. 
FLUSSER, Vilém. O mundo codificado: por uma filosofia da comunicação. São Paulo: Cosac Naif, 2007.

HUIZINGA, Johan. Homo Ludens. São Paulo: Perspectiva, 2004.

KILPP, Suzana. Introdução. In: MONTAÑO, Sonia; FISCHER, Gustavo; KILPP, Suzana. Impacto das novas mídias no estatuto da imagem. Porto Alegre: Sulina, 2012.

KILPP, Suzana. Atraição das imagens. Porto Alegre: Entremeios Editora, 20010a.

MACHADO, Arlindo. Made in Brasil. São Paulo: Senac, 2007.

MANOVICH, Lev. Software takes command. 2008. Disponível em: $\quad<$ http://softwarestudies.com/softbook/manovich_ softbook_11_20_2008.pdf>. Acesso em 10 dez. 2012.

MANOVICH, Lev. El lenguaje de los nuevos medios de comunicación: la imagen en la era digital. Buenos Aires: Paidos, 2006.

McLUHAN, Marshall. McLuhan por McLuhan: conferências e entrevistas. Rio de Janeiro: Ediouro, 2005.

McLUHAN, Marshall. Os meios de comunicação como extensões do homem. São Paulo: Cultrix Ltda, 1999.

McLUHAN, Marshall. POWERS, Bruce. La aldea global. Barcelona: Gedisa, 1993.

MONTAÑO, Sonia. A TV jogo no SBT. São Leopoldo: Universidade do Vale do Rio dos Sinos, 2007. Dissertação (Mestrado). Universidade do Vale do Rio dos Sinos, São Leopoldo, RS, 2007.

MONTAÑO, Sonia. Plataformas de vídeo: apontamentos para uma ecologia do audiovisual da web. São Leopoldo: Universidade do Vale do Rio dos Sinos, 2007. Tese (Doutorado) - Universidade do Vale do Rio dos Sinos, São Leopoldo, RS, 2012. 
MONTAÑO, Sonia; FISCHER, Gustavo; KILPP, Suzana. Impacto das novas mídias no estatuto da imagem. Porto Alegre: Sulina, 2012.

SANTAELLA, Lúcia. Culturas e artes do pós-humano. Da cultura das mídias à cibercultura. São Paulo: Paulus, 2003.

Artigo recebido em outubro de 2013 e aprovado em março de 2014. 